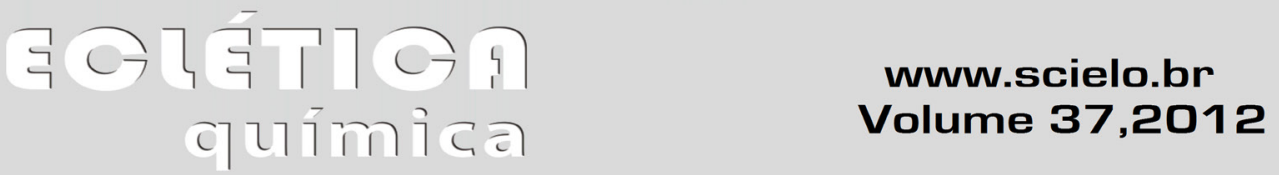

\title{
A INTERFERÊNCIA DAS ATIVIDADES ANTRÓPICAS NA QUALIDADE DA ÁGUA EM RESERVATÓRIO DE ABASTECIMENTO URBANO. ESTU- DO DE CASO: REPRESA DR. JOÃO PENIDO (JUIZ DE FORA, MG)
}

\author{
Maria Magaly Heidenreich Silva Bucci 1 e Luiz Fernando Cappa de Oliveira 2
}

1 Programa de Pós-Graduação em Ecologia - PGECOL, Instituto de Ciências Biológicas, Universidade Federal de Juiz de Fora, 36036900, Juiz de Fora, MG.

2 Núcleo de Espectroscopia e Estrutura Molecular, Instituto de Ciências Exatas, Departamento de Química, Universidade Federal de Juiz de Fora, 36036-900, Juiz de Fora, MG.

Dr. João Penido dam is the main reservoir for water supply of Juiz de Fora (MG). The forms of land use and occupation have produced negative impacts on the aquatic ecosystem. The general objective of this study was to assess the anthropogenic impact on water quality of the watershed. To this was done to characterize the quality of its waters and the parameters measured were compared with CONAMA Resolution 357/2005. It was also calculated the Water Quality Index (WQI) and the Trophic State Index (TSI). The monitoring tool has proved essential in actions involving preservation of the watershed. Ouvir

Ler foneticamente

Key words: Monitoring; Trophic State Index; Water Quality Index.

\section{INTRODUÇÃO}

O constante crescimento pela demanda de água implica na necessidade de aumentar a disponibilidade deste recurso, tendo em vista os seus múltiplos usos. Por um lado, isso representa o progresso através da construção de barragens para diversas finalidades. Em contraposição, acarreta uma série de impactos nos ecossistemas naturais decorrentes da transformação de um ambiente lótico em lêntico, provocando alterações no comportamento natural e na qualidade hídrica dos rios e córregos represados [1].

Embora o uso mais nobre que se possa dar a um recurso hídrico seja o consumo humano, os mananciais para abastecimento público no Brasil têm apresentado progressiva deterioração da qualidade de suas águas [2]. Dentre as práticas que comprometem a qualidade da água de bacias hidrográficas, podem ser citados o despejo de efluentes domésticos, o uso de fertilizantes, agrotóxicos e pesticidas, dentre outros [3-5]. Desta forma, a preocupação com a degradação dos ambientes aquáticos tem crescido no meio científico.

Outra questão relevante é que existe uma grande carência de informações a respeito de pequenas bacias hidrográficas, como é o caso da bacia da represa Dr. João Penido, situada do município de Juiz de Fora (Minas Gerais). Não há estudos sistematizados sobre a qualidade das águas do manancial, tornando-o desconhecido para a comunidade científica.

O reservatório foi construído em 1934 e desde então, vem sofrendo processos de degradação através das interferências antrópicas, apesar de estar protegido por leis municipais, estaduais e federais. Este fato pode ser evidenciado através das ocupações irregulares às margens dos corpos d'água, erosões, ausência de mata ciliar, assoreamento, bem como a proliferação de macrófitas aquáticas nas regiões de entrada dos tributários e em vários pontos do espelho d'água, indicando possível estado de eutrofização. Este fato vem causando grande preocupação, uma vez que o manancial é responsável por $65 \%$ do abastecimento público de água potável da cidade [6].

Tendo em vista a sua importância e o cenário atual em que se encontra a represa Dr. João Penido, este trabalho foi estruturado apresentando o objetivo principal de verificar a interferência antrópica na qualidade de suas águas. Para isso, foram delineados quatro objetivos específicos: caracterizar a qualidade das águas 
do reservatório e de dois principais tributários (córrego da Grama e ribeirão dos Burros), através de análises físico-químicas e microbiológicas de amostras de água; verificar o atendimento dos parâmetros analisados aos limites definidos pela Resolução 357/05 do CONAMA [7]; investigar a qualidade da água através do cálculo do Índice de Qualidade da Água (IQA); investigar o grau de trofia através do cálculo do Índice de Estado Trófico (IET).

\section{Localização e caracterização da área}

\section{Município de Juiz de Fora}

Juiz de Fora localiza-se na Zona da Mata do estado de Minas Gerais. O município está inserido na bacia do Médio do Rio Paraibuna, que pertence à Bacia Hidrográfica do Rio Paraíba do Sul. A região caracteriza-se por ser montanhosa, com altitudes médias entre 700 e 900 metros. Dentre os principais tipos de solos encontrados, podem ser citados os latossolos vermelho-amarelo, dos tipos álico e distrófico. O clima do município apresenta duas estações bem definidas: uma, que vai de outubro a abril, com temperaturas mais elevadas e maiores índices pluviométricos, e outra de maio a setembro, que se caracteriza por ser mais fria e com menor presença de chuvas. O clima da região, de acordo com a classificação de W. Koppen, é do tipo Cwa, ou seja, mesotérmico com verões quentes e úmidos. $\mathrm{O}$ município está enquadrado na região fitoecológica denominada Floresta Estacional Semidecidual (formação do bioma Mata Atlântica), típica de climas com duas estações bem definidas [6].

Represa Dr. João Penido e tributários (córrego da Grama e ribeirão dos Burros)

Apesar de estar localizado na área urbana do município, o bairro no qual está inserido o manancial apresenta características rurais, sendo formado, em sua maioria por granjas, sítios, fazendas e casas de veraneio. O bairro não possui rede de água e as famílias utilizam poços, inclusive artesianos. Não existe rede coletora de esgotos, sendo utilizados métodos rudimentares para destino final dos dejetos [6].

A área da bacia hidrográfica da represa é de 68 $\mathrm{km} 2$. A vazão regularizada do reservatório é $750 \mathrm{~L} / \mathrm{s}$ e o volume de água armazenada é aproximadamente 14.094.000 m3 (dado de 1985) [8]. Trata-se de um sistema raso, com profundidade média de 6,53 metros e máxima, de 10,90 metros, cuja área superficial é 370 ha (valores aproximados) [9].
As características de degradação citadas para a represa também fazem parte da realidade dos afluentes. As interferências antrópicas advindas do próprio represamento se refletem através da diminuição da vazão dos cursos d'água, abundância de plantas aquáticas e assoreamento, dentre outras.

Pontos de coleta

Foram definidos cinco pontos de coleta, que podem ser visualizados na Figura 1:

PT1: Ponto localizado à montante da foz do córrego da Grama na represa.

PT2: Ponto localizado entre as macrófitas, à montante da foz do ribeirão dos Burros (principal tributário) na represa.

PR1: Ponto 1 da represa, localizado na região de entrada dos principais tributários, próximo à zona fluvial.

PR2: Ponto 2 da represa, localizado próximo à zona intermediária.

PR3: Ponto 3 da represa, localizado próximo à barragem e à Estação de Tratamento de Água (ETA), ou seja, à zona lacustre.

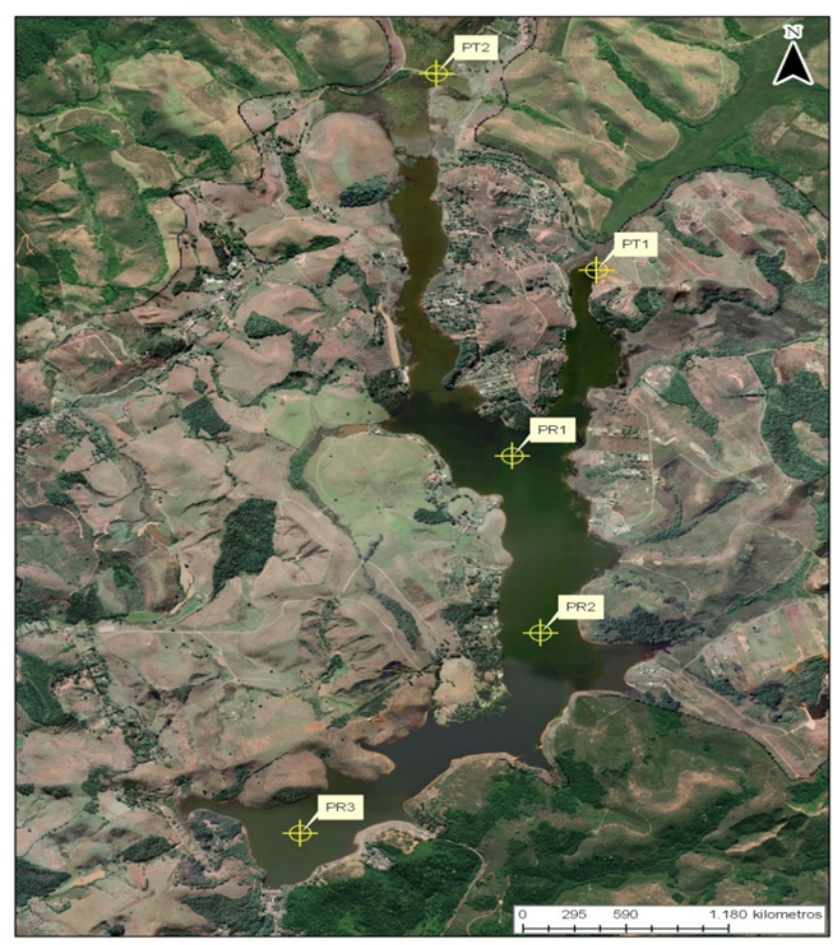

Figura 1: Ortofoto do voo aerofotogramétrico, datada de 2007, indicando os pontos de coleta: PT1: Ponto do tributário 1 - córrego da Grama; PT2: Ponto do tributário 2 - ribeirão dos Burros; PR1: Ponto 1 da represa; PR2: Ponto 2 da represa; PR3: Ponto 3 da represa. Fonte: Prefeitura de Juiz de Fora. Secretaria de Planejamento e Desenvolvimento Econômico (SPDE) [10]. 


\section{PARTE EXPERIMENTAL}

\section{Material e métodos}

Foram realizadas campanhas mensais durante um ano (período de julho de 2009 a junho de 2010). As técnicas de coleta e amostragem seguiram a NBR 9898 da ABNT [11]. Os parâmetros avaliados e seus respectivos métodos de ensaio encontram-se na tabela1. cujo cálculo é baseado em nove parâmetros, com pesos diferenciados: $\mathrm{OD}$, coliformes termotolerantes, $\mathrm{pH}$, nitrato, fósforo total, DBO, temperatura da água, turbidez e sólidos totais. As fórmulas estão de acordo com a proposta do IGAM e do Ministério de Meio Ambiente (MMA) [15]. Neste trabalho, foi utilizada planilha de cálculo do Excel, gentilmente cedida pelo IGAM.

Tabela 1- Parâmetros analisados e seus respectivos métodos de ensaio.

\begin{tabular}{|c|c|c|}
\hline Parâmetro & $\begin{array}{c}\text { Unidade de } \\
\text { medida }\end{array}$ & Método de Ensaio \\
\hline Temperatura* & ${ }^{\circ} \mathrm{C}$ & APHA (1998) ${ }^{12} 2550$ \\
\hline $\mathrm{pH}^{*}$ & $1-14$ & APHA (1998) $124500-\mathrm{H}^{+}$ \\
\hline Oxigênio dissolvido (OD) ${ }^{*}$ & $\mathrm{mg} / \mathrm{L}$ & APHA (1998) 124500 - O - G \\
\hline Condutividade elétrica & $\underline{\mathrm{u}} \mathrm{S} / \mathrm{cm}$ & APHA (1998) 122510 \\
\hline Cor & $\mathrm{mg} \mathrm{Pt} / \mathrm{L}$ & APHA (1998) $122120-$ C \\
\hline Turbidez & UNT & APHA (1998) 122130 \\
\hline Demanda Bioquímica de Oxigênio (DBO) & $\mathrm{mg} / \mathrm{L}$ & APHA (1998) 125210 - B \\
\hline Sólidos totais & $\mathrm{mg} / \mathrm{L}$ & APHA (1998) 122540 - B \\
\hline Nitrogênio total (NT) & $\mathrm{mg} / \mathrm{L}$ & APHA (1998) $124500-\mathrm{N}$ - B \\
\hline Nitrato $\left(\mathrm{NO}_{3}{ }^{-}\right)$ & $\mathrm{mg} / \mathrm{L}$ & APHA (1998) $124500-\mathrm{NO}_{3}^{-}-\mathrm{E}$ \\
\hline Nitrito $\left(\mathrm{NO}_{2}^{-}\right)$ & $\mu \mathrm{g} / \mathrm{L}$ & APHA (1998) $124500-\mathrm{NO}_{2}^{-}-\mathrm{B}$ \\
\hline Amônio $\left(\mathrm{NH}_{4}^{+}\right)$ & $\mathrm{mg} / \mathrm{L}$ & APHA (1998) $124500-\mathrm{NH}_{3}-\mathrm{F}$ \\
\hline Fósforo total (PT) & $\mathrm{mg} / \mathrm{L}$ & APHA (1998) $124500-$ P - E \\
\hline Clorofila $a$ & $\mu \mathrm{g} / \mathrm{L}$ & APHA (1998) $11.10200 \mathrm{H}$ (leitura em fluorimetro) \\
\hline Coliformes totais & $\mathrm{NMP} / 100 \mathrm{~mL}$ & APHA (1998) ${ }^{12} 9221-$ B; SILVA et al (2005) ${ }^{13}$ \\
\hline Coliformes termotolerantes & $\mathrm{NMP} / 100 \mathrm{~mL}$ & APHA (1998) 12 9221- F; SIL VA et al. (2005) ${ }^{13}$ \\
\hline
\end{tabular}

O Índice de Estado Trófico (IET) foi calculado no período de julho de 2009 a junho de 2010, de acordo com a metodologia proposta por Lamparelli [14], que é utilizada pela Companhia de Saneamento do Estado de São Paulo (CETESB) na rede de monitoramento do referido estado. A escolha é justificada por se referir a ambientes tropicais, ser de fácil aplicação e baixo custo, considerando as análises de fósforo total e clorofila a, necessárias para sua utilização. As fórmulas de cálculo estão descritas na obra de Lamparelli [14].

O Índice de Qualidade da Água (IQA) foi calculado no período de dezembro de 2009 a junho de 2010, de acordo com a metodologia proposta pelo Instituto Mineiro de Gestão das Águas (IGAM) [15], utilizada no Projeto "Águas de Minas", referente ao monitoramento das águas superficiais do estado de Minas Gerais. O IQA corresponde a um número que varia de 0 a 100,

\section{RESULTADOS E DISCUSSÃO}

Resultados dos parâmetros e atendimento aos limites definidos pelo CONAMA

Os córregos estudados e a represa estão contidos na sub bacia (SB) do ribeirão dos Burros [6]. De acordo com a Deliberação Normativa 16/96 do COPAM [16], que dispõe sobre o enquadramento dos corpos d'água da bacia do rio Paraibuna, as águas desta SB no trecho estudado, são classe 1. Os resultados dos parâmetros analisados nos pontos amostrais, a estatística descritiva, bem como os limites definidos pela Resolução 357/05 do CONAMA [7], estão apresentados na tabela 2 .

Os parâmetros coliformes totais e termotolerantes foram determinados em Número Mais Provável por $100 \mathrm{ml}(\mathrm{NMP} / 100 \mathrm{~mL})$. O método utilizado não permitiu a quantificação exata na maioria das análises 
Tabela 2 - Resultados obtidos nos pontos amostrados nos tributários e na represa.

\begin{tabular}{|c|c|c|c|c|c|c|c|}
\hline \multirow{2}{*}{ 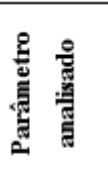 } & \multirow{2}{*}{ Resultado } & \multicolumn{2}{|c|}{$\begin{array}{c}\text { Pontos amostrais dos } \\
\text { tributários }\end{array}$} & \multicolumn{3}{|c|}{ Pontos amostrais da represa } & \multirow{2}{*}{ 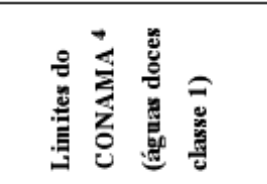 } \\
\hline & & PT1 & PT2 & PRI & PR2 & PR3 & \\
\hline \multirow{3}{*}{$\mathrm{T}\left({ }^{\circ} \mathrm{C}\right)$} & $\mathrm{M} \pm \mathrm{DP}$ & $22,73 \pm 4,31$ & $21,92 \pm 4,53$ & $24,03 \pm 3,48$ & $24,23 \pm 3,34$ & $24,15 \pm 3,34$ & \multirow{3}{*}{ - } \\
\hline & Máx. & 34,00 & 30,30 & 31,60 & 31,40 & 30,30 & \\
\hline & Min. & 17,00 & 16,00 & 19,20 & 19,80 & 18,50 & \\
\hline \multirow{3}{*}{$\begin{array}{c}\mathrm{OD} \\
(\mathrm{mg} / \mathrm{L})\end{array}$} & $\mathrm{M} \pm \mathrm{DP}$ & $5,81 \pm 1,40$ & $5,19 \pm 1,46$ & $6,35 \pm 0,71$ & $6,32 \pm 0,85$ & $6,52 \pm 1,09$ & \multirow{3}{*}{ Maior que $6,0 \mathrm{mg} / \mathrm{L}$} \\
\hline & Máx. & 7,50 & 7,90 & 7,50 & 7,50 & 8,40 & \\
\hline & Mín. & 4,00 & 3,00 & 5,10 & 5,10 & 5,10 & \\
\hline \multirow{3}{*}{$\begin{array}{l}\text { Conduti- } \\
\text { vidade } \\
(\mu \mathrm{S} / \mathrm{cm})\end{array}$} & $\mathrm{M} \pm \mathrm{DP}$ & $25,54 \pm 5,88$ & $20,91 \pm 3,82$ & $21,52 \pm 4,94$ & $21,84 \pm 4,96$ & $22,02 \pm 3,75$ & \multirow{3}{*}{ - } \\
\hline & Máx. & 31,43 & 25,80 & 30,40 & 31,59 & 30,91 & \\
\hline & Min. & 12,96 & 13,14 & 12,23 & 12,39 & 17,10 & \\
\hline \multirow{3}{*}{$\mathrm{pH}$} & $\mathrm{M} \pm \mathrm{DP}$ & $6,38 \pm 0,58$ & $5,95 \pm 0,64$ & $6,73 \pm 0,70$ & $6,79 \pm 0,67$ & $6,82 \pm 0,77$ & \multirow{3}{*}{ Entre 6,0 e 9,0} \\
\hline & Máx. & 7,60 & 7,30 & 8,00 & 7,70 & 7,60 & \\
\hline & Mín. & 5,00 & 5,00 & 5,60 & 5,70 & 5,20 & \\
\hline \multirow{3}{*}{$\begin{array}{c}\text { Cor (mg } \\
\mathrm{Pt} / \mathrm{L})\end{array}$} & $\mathrm{M} \pm \mathrm{DP}$ & $62,80 \pm 66,22$ & $88,48 \pm 60,07$ & $57,33 \pm 29,27$ & $48,11 \pm 37,65$ & $47,22 \pm 38,05$ & \multirow{3}{*}{$\begin{array}{c}\text { Cor natural do corpo } \\
\text { d'água }\end{array}$} \\
\hline & Máx. & 246,00 & 173,00 & 92,00 & 96,00 & 97,00 & \\
\hline & Min. & 0,00 & 15,00 & 12,50 & 0,00 & 0,00 & \\
\hline \multirow{3}{*}{$\begin{array}{c}\text { Turbidez } \\
\text { (UNT) }\end{array}$} & $\mathrm{M} \pm \mathrm{DP}$ & $26,64 \pm 32,65$ & $52,70 \pm 51,52$ & $20,64 \pm 14,32$ & $18,34 \pm 17,01$ & $17,74 \pm 16,33$ & \multirow{3}{*}{40,0 UNT } \\
\hline & Máx. & 115,00 & 126,70 & 40,60 & 41,80 & 40,80 & \\
\hline & Mín. & 1,00 & 2,26 & 2,96 & 1,00 & 1,00 & \\
\hline \multirow{3}{*}{$\begin{array}{c}\text { Sólidos } \\
\text { totais } \\
(\mathrm{mg} / \mathrm{L})\end{array}$} & $\mathrm{M} \pm \mathrm{DP}$ & $32,29 \pm 45,44$ & $36,86 \pm 63,23$ & $37,86 \pm 36,35$ & $25,43 \pm 24,42$ & $41,57 \pm 52,28$ & \multirow{3}{*}{$500,0 \mathrm{mg} / \mathrm{L}$} \\
\hline & Máx. & 135,00 & 180,00 & 120,00 & 80,00 & 160,00 & \\
\hline & Min. & 10,00 & 10,00 & 20,00 & 10,00 & 19,00 & \\
\hline \multirow{3}{*}{$\begin{array}{c}\text { DBO } \\
(\mathrm{mg} / \mathrm{L})\end{array}$} & $\mathrm{M} \pm \mathrm{DP}$ & $11,47 \pm 3,55$ & $8,87 \pm 3,17$ & $10,76 \pm 2,06$ & $6,90 \pm 3,56$ & $9,83 \pm 2,74$ & \multirow{3}{*}{$3,0 \mathrm{mg} / \mathrm{L}$} \\
\hline & Máx. & 16,21 & 14,73 & 13,67 & 14,50 & 13,50 & \\
\hline & Min. & 5,71 & 4,11 & 7,60 & 2,70 & 4,32 & \\
\hline \multirow{3}{*}{$\begin{array}{c}\text { Amônio } \\
(\mathrm{mg} / \mathrm{L})\end{array}$} & $\mathrm{M} \pm \mathrm{DP}$ & $0,08 \pm 0,04$ & $0,09 \pm 0,11$ & $0,10 \pm 0,05$ & $0,08 \pm 0,05$ & $0,07 \pm 0,04$ & \multirow{3}{*}{$\begin{array}{l}3,7 \mathrm{mg} / \mathrm{L}(\mathrm{pH} \leq 7,5) ; \\
2,0 \mathrm{mg} /(7,5<\mathrm{pH} \leq \\
8,0) ; 1,0 \mathrm{mg} / \mathrm{L}(8,0< \\
\mathrm{pH} \leq 8,5) ; \quad 0,5 \\
\mathrm{mg} / \mathrm{L}(\mathrm{pH}>8,5)\end{array}$} \\
\hline & Máx. & 0,18 & 0,40 & 0,17 & 0,15 & 0,13 & \\
\hline & Mín. & 0,01 & 0,01 & 0,03 & 0,01 & 0,01 & \\
\hline & $\mathrm{M} \pm \mathrm{DP}$ & $1,13 \pm 0,77$ & $1,23 \pm 0,90$ & $0,85 \pm 0,70$ & $0,67 \pm 0,68$ & $0,70 \pm 0,59$ & \\
\hline$(\mu \mathrm{g} / \mathrm{L})$ & Máx. & 2,22 & 2,26 & 2,18 & 2,03 & 1,55 & $1,0 \mathrm{mg} / \mathrm{L}$ \\
\hline & Mín. & 0,03 & 0,20 & 0,00 & 0,00 & 0,00 & \\
\hline Nitrato & $\mathrm{M} \pm \mathrm{DP}$ & $0,554 \pm 0,261$ & $0,442 \pm 0,382$ & $0,561 \pm 0,360$ & $0,486 \pm 0,323$ & $0,467 \pm 0,294$ & \\
\hline$(\mathrm{mg} / \mathrm{L})$ & Máx. & 0,919 & 1,143 & 1,015 & 0,906 & 0,859 & $10,0 \mathrm{mg} / \mathrm{L}$ \\
\hline & Min. & 0,222 & 0,059 & 0,126 & 0,190 & 0,194 & \\
\hline & $\mathrm{M} \pm \mathrm{DP}$ & $0,957 \pm 0,222$ & $0,841 \pm 0,311$ & $0,891 \pm 0,355$ & $0,771 \pm 0,283$ & $0,792 \pm 0,262$ & Determina limites \\
\hline$(\mathrm{mg} / \mathrm{L})$ & Máx. & 1,312 & 1,537 & 1,492 & 1,299 & 1,195 & $\begin{array}{l}\text { quando o nitrogênio for } \\
\text { fator limitante para }\end{array}$ \\
\hline & Mín. & 0,616 & 0,284 & 0,463 & 0,498 & 0,390 & eutrofização \\
\hline & $\mathrm{M} \pm \mathrm{DP}$ & $0,082 \pm 0,129$ & $0,074 \pm 0,126$ & $0,066 \pm 0,114$ & $0,066 \pm 0,100$ & $0,068 \pm 0,116$ & \\
\hline$(\mathrm{mg} / \mathrm{L})$ & Máx. & 0,470 & 0,460 & 0,420 & 0,360 & 0,420 & $0,020 \mathrm{mg} / \mathrm{L}$; tributários \\
\hline & Min. & 0,009 & 0,013 & 0,007 & 0,006 & 0,004 & $\begin{array}{l}\text { diretos de ambientes } \\
\text { lênticos: } 0,025 \mathrm{mg} / \mathrm{L} \text {. }\end{array}$ \\
\hline Clorofila & $\mathrm{M} \pm \mathrm{DP}$ & $2,53 \pm 0,68$ & $1,71 \pm 0,79$ & $3,35 \pm 0,88$ & $3,14 \pm 0,87$ & $3,18 \pm 0,55$ & \\
\hline$a(\mu \mathrm{g} / \mathrm{L})$ & Máx. & 3,75 & 2,85 & 5,00 & 4,85 & 4,05 & $10 \mu \mathrm{g} / \mathrm{L}$ \\
\hline & Min. & 1,75 & 0,30 & 2,35 & 2,05 & 2,35 & \\
\hline
\end{tabular}


laboratoriais realizadas, mas observou-se que sua presença na água é baixa. Por este motivo, não foi apresentada estatística descritiva dos mesmos. Os resultados encontram-se na tabela 3 .

Tabela 3 - Resultados de coliformes termotolerantes (CTer) e totais (CTot) (NMP/100 mL) em águas de tributários e represa.

\section{Oxigênio dissolvido (OD)}

A represa apresentou melhores índices de OD que os

afluentes, fato também observado na rede de monitoramento das águas superficiais do estado de São

\begin{tabular}{|c|c|c|c|c|c|c|c|c|c|c|}
\hline \multirow{2}{*}{ Mês } & \multicolumn{2}{|c|}{ PT1 } & \multicolumn{2}{|c|}{ PT2 } & \multicolumn{2}{|c|}{ PRI } & \multicolumn{2}{|c|}{ PR2 } & \multicolumn{2}{|c|}{ PR3 } \\
\hline & $\mathbf{C}_{\text {Ter }}$ & $\mathbf{C}_{\text {Tot }}$ & $\mathbf{C}_{\text {Ter }}$ & $\mathbf{C}_{\text {Tot }}$ & $\mathbf{C}_{\text {Ter }}$ & $\mathbf{C}_{\text {TIt }}$ & $\mathbf{C}_{\text {Ter }}$ & $\mathbf{C}_{\text {Tot }}$ & $\mathbf{C}_{\text {Ter }}$ & $\mathbf{C}_{\text {Tot }}$ \\
\hline $\mathrm{dez} / 09$ & $<3$ & 14 & $<3$ & 3,6 & $<3$ & $<3$ & $<3$ & $<3$ & $<3$ & $<3$ \\
\hline $\mathrm{ian} / 10$ & $<3$ & $<3$ & $<3$ & $<3$ & $<3$ & $<3$ & $<3$ & $<3$ & $<3$ & $<3$ \\
\hline $\mathrm{fev} / 10$ & $<3$ & 240 & $<3$ & 240 & $<3$ & 240 & $<3$ & 50 & $<3$ & 23 \\
\hline $\operatorname{mar} / 10$ & $<3$ & 240 & $<3$ & 1600 & $<3$ & 130 & $<3$ & 80 & $<3$ & 130 \\
\hline $\mathrm{abr} / 10$ & $<3$ & 220 & $<3$ & 33 & $<3$ & 22 & $<3$ & 17 & $<3$ & 30 \\
\hline $\mathrm{mai} / 10$ & $<3$ & 23 & $<3$ & 30 & $<3$ & 50 & $<3$ & 60 & $<3$ & 27 \\
\hline iun $/ 10$ & $<3$ & 33 & 4 & 80 & $<3$ & 80 & $<3$ & 33 & 4 & 80 \\
\hline
\end{tabular}
nos pontos dos

O período de monitoramento de cada parâmetro teve início conforme a logística e recursos disponíveis para cada um. Desta forma, as análises foram realizadas no período de julho de 2009 a junho de 2010, exceto para os parâmetros a seguir: amônio, NT e nitrito, que tiveram o início, respectivamente em agosto, setembro e outubro de 2009; sólidos totais e coliformes, em dezembro de 2009; nitrato, em janeiro de 2010.

Os parâmetros que estiveram em desconformidade com a Resolução 357/05 do CONAMA [7] e suas respectivas porcentagens nos pontos amostrais estão apresentadas na figura 2. Os demais parâmetros analisados, quando contemplados por esta norma estiveram de acordo com os limites estabelecidos.

Análise dos parâmetros individuais e as possíveis relações com as atividades antrópicas nos ambientes estudados

Temperatura da água

Observou-se homogeneidade nas temperaturas da água do reservatório, com média superior às temperaturas das águas dos afluentes. Isso se deve ao grande volume de água armazenada no mesmo e ao seu alto calor específico, que permite maior conservação do calor e menor variação de temperatura ao longo do tempo.

tributários podem ser indicativas de entradas de carga orgânica provenientes de efluentes domésticos e/ou escoamento superficial.

Acredita-se também que as macrófitas interferem nesses resultados, pois são abundantes nessas regiões. Essas plantas fornecem grande quantidade de oxigênio para o meio aquático, porém, após completarem seu ciclo de vida, entram em processo de decomposição e podem passar a ser consumidoras de OD da massa líquida. Além disso, elas também podem aumentar a resistência à livre movimentação de ar, diminuindo a ação dos ventos sobre o espelho d'água e, contribuindo desta forma, para a redução da concentração de OD. Outro ponto que deve ser considerado é que as macrófitas possibilitam maior retenção de material orgânico transportado de locais à montante da bacia hidrográfica, que ao ser degradado pelos micro-organismos aeróbios, proporcionam consumo de OD.

A menor média de todos os pontos (Tabela 2) e a maior porcentagem de resultados em desconformidade com os limites estabelecidos pelo CONAMA [7] (Figura 2) ocorreram no ribeirão dos Burros (PT2). Além do OD, os outros parâmetros que estiveram em desacordo com esta norma (PT, pH, DBO e turbidez) indicaram grande impacto neste ambiente (Figura 2). A justificativa está na rede de esgotos clandestina construída pelos moradores do local, direcionando os efluentes domésticos para o ribeirão, à montante do PT2. 
As reações de degradação da matéria orgânica presente nestes resíduos consome OD do meio. Os resultados obtidos mostram claramente a interferência antrópica provocando deterioração do ecossistema aquático, que fica mais vulnerável devido à ausência de mata ciliar.

As concentrações mínimas observadas no reservatório ocorreram no período de estiagem (maio a julho) devido a menor diluição de matéria orgânica e outras substâncias na água. Nos afluentes, as mínimas ocorreram em mês de cheia (dezembro) devido ao escoamento superficial da bacia de drenagem.

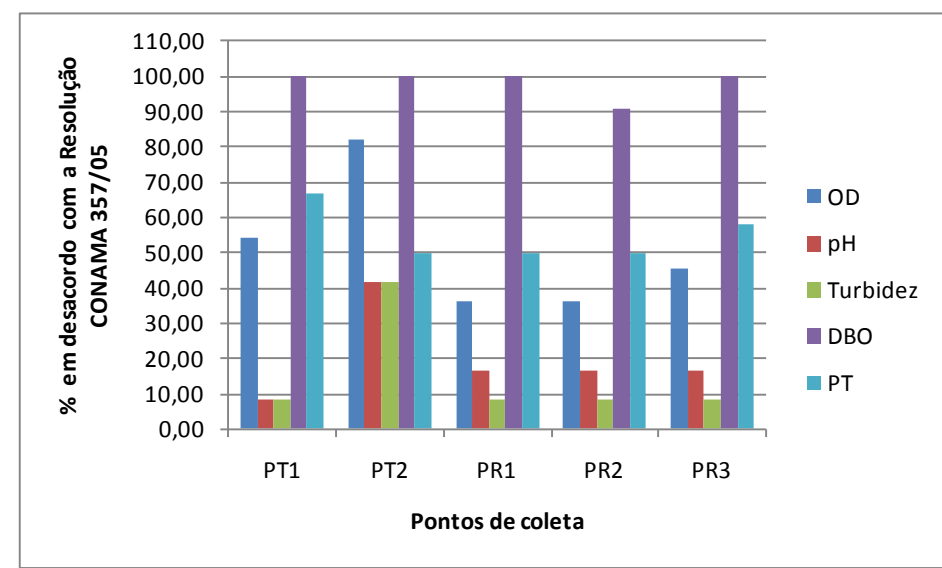

Figura 2: Porcentagens de resultados dos parâmetros analisados em desconformidade com os limites definidos pelo CONAMA [7] nos pontos amostrais estudados.

\section{Condutividade elétrica}

O CONAMA [7] não estabelece limites para a condutividade. Então, adotou-se neste trabalho o valor de referência utilizado pela CETESB, que considera níveis superiores a $100 \mu \mathrm{S} / \mathrm{cm}$ (microsiemens por centímetro) como indicativo de ambientes impactados [17]. Os valores máximos foram observados no período chuvoso e não atingiram este limite (Tabela 2). Estes resultados podem estar relacionados com os máximos obtidos para cor e turbidez nas mesmas amostras (exceto para o PT2). Também houve coincidência entre os máximos registrados para os três parâmetros citados, no mês de novembro para o PT1, e em abril para os pontos da represa. Estas observações evidenciam o transporte de íons, além de inúmeras substâncias através dos sedimentos, para os corpos d'água através do runoff [18] da bacia de drenagem.

Os valores mínimos registrados foram observados no período de estiagem.

A maior média observada ocorreu no córrego da Grama (PT1). Este tributário recebe diretamente ma- teriais de origem alóctone provenientes do talude desprovido de vegetação em sua margem esquerda.

\section{Potencial Hidrogeniônico $(p H)$}

$\mathrm{O} \mathrm{pH}$ pode ser considerado como uma das variáveis ambientais mais importantes e ao mesmo tempo, uma das mais difíceis de se interpretar, devido a inúmeros fatores que podem influenciá-lo. Normalmente o pH de águas doces é mantido em torno da neutralidade [19], através do sistema de tamponamento baseado nas concentrações carbonato e bicarbonato em solução, provenientes do $\mathrm{CO} 2$. As florações de algas ou macrófitas no ambiente interferem nesse sistema tampão, podendo-se observar aumento de acidez ou alcalinidade da água. Se há aumento da fotossíntese, o $\mathrm{pH}$ tende a aumentar, pois há consumo de $\mathrm{CO} 2$ no processo. Porém, os íons carbonato ou bicarbonato existentes no meio o tampona, mantendo o $\mathrm{pH}$ em torno de 6,5. Por outro lado, os organismos heterotróficos tendem a baixar o $\mathrm{pH}$ da massa líquida, pois os processos de decomposição e respiração liberam CO2 [19], dentre outras substâncias no ambiente.

$\mathrm{Na}$ análise dos resultados obtidos neste trabalho, observou-se que a variação sazonal foi bastante significativa. Nas medições feitas no período de estiagem, todos os parâmetros estiveram em conformidade com os limites definidos pelo CONAMA [7]. Entre dezembro de 2009 e abril de 2010 (cheia), o PT2 apresentou $\mathrm{pH}$ em desconformidade com esta norma em todas as medições, sendo obtidos valores que variaram de 5,0 a 5,9. Dezembro foi o primeiro mês com maior impacto de águas de chuva, sendo registrados $315,6 \mathrm{~mm}$, de acordo com a Estação Pluviométrica da Represa Dr. João Penido (EPRJP). Em janeiro, apenas o PT1 esteve em conformidade e em fevereiro, os ambientes retornaram ao equilíbrio, exceto o PT2, onde o $\mathrm{pH}$ se normalizou somente em maio. Águas de chuva podem interferir no $\mathrm{pH}$ dos ecossistemas aquáticos continentais, pois normalmente são ácidas [20], com $\mathrm{pH}$ entre 5,0 e 6,0 . O efeito é mais acentuado, quando os ambientes possuem baixa capacidade de tamponamento e isso foi observado no PT2, entre dezembro e abril. Este ponto de coleta localiza-se entre as plantas e provavelmente isso está interferindo no sistema tampão do ecossistema aquático. Sendo assim, a represa e o córrego da Grama (PT1) demonstraram melhor capacidade de recuperação do equilíbrio iônico do sistema, após o stress provocado pela água de chuva.

Ainda com relação ao ribeirão dos Burros, 
acredita-se que outros fatores além das águas pluviais, contribuíram para a diminuição do $\mathrm{pH}$ do meio aquático. Foi observada uma relação entre $\mathrm{pH}$, cor e turbidez, no referido período chuvoso. Associada às maiores médias para a cor e turbidez, observou-se menor média para o $\mathrm{pH}$ do que os outros pontos amostrais. A justificativa pode estar abundância de plantas aquáticas em torno do PT2. O incremento na cor e diminuição do $\mathrm{pH}$ pode ser explicado pela presença de colóides orgânicos, como os ácidos húmico e fúlvico, substâncias naturais resultantes da decomposição parcial de compostos orgânicos presentes em folhas de vegetais e em outros substratos [17]. Com o aumento das chuvas, o transporte de materiais ficou mais intenso justificando o aumento da turbidez. Os efeitos são potencializados pela disposição inadequada de esgotos no córrego.

A menor média obtida (Tabela 2) e a maior porcentagem de medições referentes ao $\mathrm{pH}$ em desacordo com o CONAMA [7] (Figura 2), foram obtidas para o ribeirão dos Burros (PT2) pelos motivos já explanados. Para o reservatório, a menor média foi obtida no PR1 (Tabela 2), por sofrer forte influência das águas tributárias.

\section{Cor verdadeira e turbidez}

Esses parâmetros serão discutidos em conjunto, uma vez que foi observada uma variação semelhante entre os mesmos nos resultados. A cor de uma amostra de água está associada à presença de sólidos dissolvidos, principalmente material em estado coloidal orgânico e inorgânico. Substâncias presentes na água, como substâncias húmicas, compostos de ferro [19], ou produtos resultantes de reações químicas provenientes do metabolismo do ecossistema, também provocam alterações na cor da água. A turbidez relaciona-se à presença de sólidos em suspensão, tais como, partículas inorgânicas (areia, argila e silte), detritos orgânicos, algas, bactérias, plâncton, dentre outros [20].

As médias relativas aos dois parâmetros foram maiores nos tributários, se comparadas ao reservatório, fato também constatado na rede de monitoramento do estado de São Paulo [14]. As maiores médias para a cor e turbidez, bem como a maior porcentagem de resultados de turbidez em desacordo com o CONAMA [7] foram obtidas no ribeirão dos Burros (PT2) (Tabela 2 e Figura 2), justificado pelas características lóticas deste ambiente e pela presença de esgotos no córrego (o CONAMA [7] não estabelece limites para a cor, referente a águas doces classe 1). O grande desvio padrão demons- tra a grande variação sazonal para estes parâmetros.

Ainda em relação ao ribeirão dos Burros, foi feita uma observação referente à interferência antrópica no córrego, nas campanhas de dezembro de 2009 e janeiro de 2010. As macrófitas haviam sido arrancadas ou cortadas e deixadas na água, à montante do ponto de coleta. Foram observados na análise das amostras, respectivamente, em dezembro e janeiro: menores valores de OD $(3,00$ e $5,10 \mathrm{mg} / \mathrm{L})$ e $\mathrm{pH}(5,0$ e 5,7$)$, maiores valores para a cor $(97,0$ e $85,0 \mathrm{mg} \mathrm{Pt} / \mathrm{L})$ e turbidez $(30,0$ e 25,0 UNT) do que os outros pontos de coleta. Acredita-se que a retirada das plantas provocou revolvimento e ressuspensão de sedimentos do fundo, alterando na qualidade da água do ribeirão. Nos meses seguintes à ocorrência, no período de fevereiro a maio, foram observados respectivamente, os maiores valores obtidos para a cor $(173,0 ; 171,0 ; 106,0$ e $155,0 \mathrm{mg} \mathrm{Pt} / \mathrm{L})$ e turbi$\operatorname{dez}(121,0 ; 120,3 ; 126,7$ e 105,4 UNT) no PT2. Em fevereiro e março, também houve incremento de PT $(0,11$ e $0,10 \mathrm{mg} / \mathrm{L})$, nitrato $(0,49$ e $1,14 \mathrm{mg} / \mathrm{L})$ e NT $(0,84$ e $1,54 \mathrm{mg} / \mathrm{L})$, respectivamente. Acredita-se que os nutrientes que tinham sido absorvidos pelas plantas foram sendo disponibilizados para o ambiente, à medida que as mesmas foram deixadas na água. Estas observações indicam que a capacidade das macrófitas funcionarem como um filtro para o corpo hídrico ficou prejudicada.

Para a represa, as maiores médias de cor e turbidez foram obtidas no PR1 (Tabela 2), justificado por localizar-se em uma região de grande mistura [18]. Apesar de pouca diferença significativa, os valores decrescentes das médias relativas a estes parâmetros obtidas do PR1 para o PR3 (Tabela 2), refletem a tendência geral do efeito da diminuição da sedimentação proveniente da zonação longitudinal ao longo da represa, da zona fluvial para a lacustre [18].

Os valores máximos obtidos para a cor e turbidez nos três pontos do reservatório ocorreram em abril (Tabela 2). Este fato pode estar associado à formação de produtos provenientes de reações químicas relativas ao metabolismo do ecossistema, que intensificam a cor da água. Levando-se em conta que a represa é um ambiente raso, fatores como correntes de vento que revolvem os sedimentos do fundo podem também ter sido a causa do processo [21].

$\mathrm{Na}$ represa Dr. João Penido, os valores de turbidez variaram de 1,00 a 41,80 UNT, sendo que a mesma é desprovida de mata ciliar em quase toda a sua extensão. Estes valores são considerados altos, se comparados com bacias hidrográficas recobertas por floresta de Mata Atlântica, que são da ordem de 0,15 a 4,9 UNT 
[22]. Isso mostra que a floresta protege o solo contra a erosão, preservando os corpos d'água.

Os valores máximos para cor e turbidez (Tabela 2) foram obtidos nos afluentes, no período de cheia e a ausência de mata ciliar contribuiu para este resultado. Considerando que os valores máximos para o reservatório ocorreram no período de estiagem, pode-se inferir que a pluviosidade interfere mais na cor e turbidez dos afluentes do que no reservatório.

\section{Sólidos totais}

Todos os resultados obtidos neste estudo atenderam aos padrões definidos pelo CONAMA [7]. Os máximos para todos os pontos (Tabela 2) foram registrados em dezembro, fato associado à alta pluviosidade deste mês $(315,6 \mathrm{~mm}$, de acordo com a EPRJP). Na represa, a ocorrência foi no PR3 e foi constatado à montante deste ponto amostral, movimento de terra e assoreamento na margem direita em novembro e dezembro. Neste último mês, a máxima concentração de sólidos totais pode estar relacionada ao alto valor para a DBO $(13,09 \mathrm{mg} / \mathrm{L})$, baixo índice de OD $(5,60 \mathrm{mg} / \mathrm{L})$ e mínimo valor para o $\mathrm{pH}(5,20)$, obtidos para a mesma amostra. Fato semelhante ocorreu à montante do PR1, também em dezembro. Observou-se movimento de terra e queima de vegetação na margem direita, que deixaram o solo exposto. Neste mês, a máxima concentração de sólidos totais para o PR1 também pode estar associada aos baixos índices de OD $(5,90 \mathrm{mg} / \mathrm{L})$ e $\mathrm{pH}(5,80)$, bem como altos valores para a DBO $(10,66 \mathrm{mg} / \mathrm{L})$. As intensas chuvas de dezembro potencializaram os efeitos das interferências antrópicas observadas no entorno do manancial para os dois pontos citados.

A maior média de todos os pontos foi observada no PR3 (Tabela 2). Isso demonstra que a região próxima à barragem da represa é receptora de sedimentos provenientes de processos erosivos das margens à montante, bem como do escoamento superficial de toda a bacia de drenagem. Esta zona deveria apresentar menores concentrações de sólidos totais, uma vez que está próxima à zona lacustre e à captação de água (ETA).

\section{Demanda Bioquímica de Oxigênio (DBO)}

Todos os resultados estão em desacordo com o CONAMA [7] (Figura 2), exceto no mês de janeiro para o PR2, onde foi obtido o valor mínimo de 2,70 mg/L (Tabela 2).

O valor máximo registrado ocorreu no cór- rego da Grama (PT1), em abril (Tabela 2). As intensas chuvas de março $(320,6 \mathrm{~mm}$, de acordo com a EPRJP) provocaram o revolvimento e ressuspensão de sedimentos acumulados em toda a área brejosa coberta por macrófitas na margem direita e à montante do ponto de coleta, bem como o aumento do volume da água do córrego. O transporte foi facilitado pelo maior fluxo, incrementando o teor de carga orgânica na água. Este afluente também apresentou a maior média e a justificativa está na vulnerabilidade deste ambiente ao escoamento superficial. Sua margem esquerda possui um pequeno talude que frequentemente sofre capina e remoção de vegetação ciliar, pelos moradores do entorno, fato que compromete a qualidade hídrica deste córrego. As características lênticas proporcionadas pela proliferação de macrófitas em sua margem direita, também favorecem o acúmulo de nutrientes e carga orgânica na água.

A influência da estiagem sobre a DBO pode ser percebida em setembro de 2009. Fazendo uma análise espacial, neste mês todos os pontos apresentaram altos valores de $\mathrm{DBO}$, inclusive foi obtido o máximo para a represa no PR2 (Tabela 2). No mês anterior choveu apenas 7,25 mm (EPRJP), levando a uma maior concentração de carga orgânica na água.

Em janeiro de 2010, interferências antrópicas provocaram erosões na margem direita da represa à montante do PR3. As alterações na qualidade da água foram percebidas, fato que causa preocupação por estar próximo à ETA. Além da concentração máxima de DBO para este ponto (Tabela 2), também houve valores em desacordo o CONAMA [7] para o $\mathrm{pH}(5,8)$, OD $(5,8$ $\mathrm{mg} / \mathrm{L})$ e PT $(0,033 \mathrm{mg} / \mathrm{L})$, na mesma amostra.

Íons amônio (NH4+), nitrito (NO2-) e nitrato (NO3-).

O nitrogênio pode ser encontrado nas águas basicamente em duas formas: reduzida (nitrogênio orgânico e amoniacal) e oxidada (nitrito e nitrato). Diversas são as fontes que contribuem para a presença deste elemento nas águas naturais, mas geralmente, os esgotos sanitários constituem a principal [17].

Neste estudo, todos os resultados referentes a estes parâmetros estiveram em conformidade com os limites estabelecidos pelo CONAMA [7].

Através das formas de nitrogênio presentes no meio aquático, pode-se associar a proximidade da fonte de poluição. Se a análise de uma amostra de água de um corpo hídrico demonstrar predominância de nitrogênio orgânico e amoniacal, significa que as descargas de esgotos estão próximas. Se prevalecerem os íons nitrito e nitrato, pode-se inferir que estão distantes, pois es- 
tas são as formas finais de oxidação do nitrogênio [17]. Os resultados indicaram que todos os valores de nitrato foram superiores aos de amônio, no período monitorado. Isso significa que próximo aos pontos amostrais, provavelmente não existe fonte pontual de poluição por efluentes domésticos nos corpos d'água [17]. O ponto de lançamento clandestino de esgotos citado anteriormente, à montante do $\mathrm{PT} 2$, não é próximo o suficiente para que o amônio prevaleça sobre o nitrato na água. Devem existir condições favoráveis no meio que promovem a oxidação do amônio a nitrato, até atingir o PT2.

Apesar da pouca diferença significativa, os resultados das médias de nitrato e amônio (Tabela 2) dos pontos amostrais do reservatório refletem a tendência geral de diminuição da concentração destes íons na água, da região fluvial para a lacustre, proveniente da zonação longitudinal ao longo do mesmo [18].

Algumas observações feitas em campo relativas à represa indicam a interferência antrópica na qualidade da água. A máxima concentração para o nitrato (PR1) em março (Tabela 2) coincidiu com valores acima da média para este ponto em relação aos seguintes parâmetros: cor $(83,0 \mathrm{mg} \mathrm{Pt} / \mathrm{L})$, turbidez $(35,0 \mathrm{UNT})$, DBO (12,15 mg/L), PT (0,074 mg/L) e NT (1,35 mg/L). $\mathrm{O}$ fato pode estar relacionado ao assoreamento proveniente de movimentações de terra observadas em vários locais da margem direita, à montante deste ponto amostral, indicando o aporte de materiais presentes no solo para a represa. O maior índice pluviométrico do período também foi registrado neste mês, o que agravou a situação.

\section{Nitrogênio total (NT)}

O NT corresponde à soma das concentrações de nitrogênio orgânico, amônio, nitrito e nitrato. A Resolução 357/05 do CONAMA [7] determina em seu artigo 10, limites para águas doces enquadradas nas classes 1 e 2, quando o nitrogênio for fator limitante para eutrofização. Como não há estudos para saber se os ambientes monitorados são limitados por fósforo ou nitrogênio, não foi possível verificar se os valores encontrados atendem à referida norma.

Na represa, alterações na qualidade da água puderam ser percebidas na zona próxima à ETA (PR3) e acredita-se que possuem relação com alguns parâmetros. Em fevereiro, foram obtidos valores máximos para o NT e nitrato (Tabela 2), bem como valores acima da média para a cor $(86,0 \mathrm{mg} \mathrm{Pt} / \mathrm{L})$, turbidez $(35,0 \mathrm{UNT})$ e PT $(0,11 \mathrm{mg} / \mathrm{L})$. O fato pode estar associado com a queima de vegetação à montante, na margem direita da represa. Esta prática é considerada crime ambiental, conforme artigo 41 da Lei $\mathrm{n}^{\circ}$ 9605/98 (Lei de Crimes Ambientais [23]). O solo ficou exposto, facilitando o aporte de material alóctone para a represa.

A maior média registrada para os afluentes foi no PT1, justificado pela presença de esgotos no córrego, e para a represa ocorreu no PR1, por estar próximo à zona fluvial.

Os valores máximos obtidos para o NT coincidiram com os máximos para o nitrato em todos os pontos amostrais e ocorreram em período de cheia, exceto no PR1, onde o máximo do NT ocorreu na estiagem (junho).

\section{Fósforo total (PT)}

Diversas são as fontes de fósforo em águas naturais, mas as principais são os esgotos sanitários. As águas drenadas em áreas agrícolas e urbanas também podem provocar a presença excessiva deste elemento nos corpos hídricos [17].

A literatura informa que as maiores elevações de PT em rios do Canadá estão relacionadas ao escoamento superficial provocado por eventos de chuvas após épocas secas, sendo que o incremento está relacionado às fontes não pontuais de poluição [24]. Os picos de PT observados em julho de 2009 nos cinco pontos amostrais (Tabela 2) ocorreram após curto período de seca, seguido de eventos de chuvas. Este fato, aliado às fontes difusas de poluição contribuíram para esta ocorrência. A concentração máxima (Tabela 2) e a maior porcentagem de resultados em desacordo com o CONAMA [7] (Figura 2) ocorreram no PT1, justificado pelas características lênticas deste ambiente que favorecem o acúmulo de nutrientes. Na represa, a máxima se deu no PR1, o que era de se esperar, por estar próximo à zona fluvial.

Porém, fato que chamou a atenção foi que, apesar da pouca diferença, a maior média dos pontos da represa foi obtida no PR3 (os parâmetros sólidos totais e condutividade elétrica também apresentaram a maior média da represa, no PR3) (Tabela 2). Isso indica que a zona lacustre está sendo impactada por fontes de fósforo. Estas regiões, geralmente são pobres em relação a este nutriente $[25,26]$, porém, isso não foi observado para a represa Dr. João Penido. Conforme já foi comentado, esta zona da represa é região receptora de sedimentos e como eles transportam fósforo, ocorre o incremento deste parâmetro na água.

As médias dos afluentes foram maiores, se 
comparadas ao reservatório, fato também observado por Lamparelli [14] na rede de monitoramento do estado de São Paulo.

\section{Clorofila a}

A clorofila a é um dos pigmentos responsáveis pelo processo fotossintético. Representa aproximadamente de 1 a $2 \%$ do peso seco do material orgânico em todas as algas planctônicas. Por isso, é considerada a principal variável indicadora de estado trófico dos ambientes aquáticos [17].

Todos os resultados obtidos neste estudo atenderam aos limites do CONAMA [7]. Pagioro et al. [26] citam que existe uma relação positiva entre a clorofila a e o PT, indicando que ele estimula a biomassa fitoplanctônica. Esta abordagem foi evidenciada neste estudo, através dos picos registrados para o PT em todos os pontos em julho de 2009, coincidindo com as concentrações máximas para a clorofila a no PT1, PR2 e PR3 (Tabela 2). O PR1 teve concentração de clorofila a próxima à máxima obtida para esta mesma amostra $(4,55 \mu \mathrm{g} / \mathrm{L})$. Nesse mês, somente para o PT2, a relação entre os parâmetros foi inversa, sendo obtida a mínima da clorofila a na mesma amostra em que foi registrada a máxima para o PT (Tabela 2). Lamparelli [14] cita que vários fatores influenciam a produtividade do fitoplâncton, além da disponibilidade de nutrientes. Fatores físicos, como a velocidade da água, e as consequentes taxas de sedimentação, influenciam a transparência da água e a turbulência do ambiente. O maior fluxo de água neste ponto amostral pode explicar esta relação inversa ocorrida em julho para os parâmetros PT e clorofila a no PT2.

A represa apresentou maiores médias para a clorofila a, se comparada aos córregos, fato também observado nos corpos d'água do estado de São Paulo [14]. Por ser ambiente lêntico, o reservatório proporciona maior incidência de luz e acúmulo de nutrientes, favorecendo o incremento da concentração de clorofila a.

A maior média dos córregos ocorreu no PT1, justificada pelas características lênticas deste curso d'água. A maior média da represa ocorreu no PR1, demonstrando maior tendência à eutrofização deste ponto, inclusive por estar mais próximo da entrada dos tributários.

Interferências antrópicas puderam ser observadas no córrego da Grama (PT1) em junho de 2010. Sua margem esquerda apresentou muita terra exposta proveniente de capina e remoção da vegetação ciliar. As análises da amostra de água indicaram valor mínimo para a clorofila a (Tabela 2) e valores acima da média para a cor $(75,0 \mathrm{mg} \mathrm{Pt} / \mathrm{L})$, turbidez $(40,0 \mathrm{UNT})$ e NT $(1,12 \mathrm{mg} / \mathrm{L})$. As alterações na qualidade hídrica também puderam ser percebidas através de valores que não atenderam aos limites estabelecidos pelo CONAMA [7], como PT $(0,05 \mathrm{mg} / \mathrm{L}), \mathrm{DBO}(9,46 \mathrm{mg} / \mathrm{L})$ e OD $(4,5$ $\mathrm{mg} / \mathrm{L})$.

Coliformes termotolerantes e Coliformes totais

As bactérias do grupo coliformes são consideradas as principais indicadoras de contaminação fecal [17]. Foi verificado que todas as amostras apresentaram resultados bem inferiores aos limites definidos pelo CONAMA [7, 27], sendo todas consideradas "próprias" e de "excelente" qualidade, em relação a este parâmetro (Tabela 3). Sua origem na água é proveniente de prováveis contaminações por esgotos domésticos e de material fecal oriundo da criação de animais no entorno do manancial. Esses micro-organismos ficam armazenados no solo e com as chuvas são carreados para os corpos d'água.

As Resoluções 357/05 e 274/00 do CONAMA $[7,27]$ não determinam limites para coliformes totais, mas alguns pontos devem ser considerados. Houve incremento deste parâmetro durante os meses de fevereiro e março de 2010 (Tabela 3), indicando relação direta com o período chuvoso, fato também observado por Haddad [24] no monitoramento do rio São Miguel (MG). Constatou-se também que os pontos localizados na parte alta da represa (PT1, PT2 e PR1) indicaram maior contaminação por este micro-organismo.

ÍNDICE DE QUALIDADE DA ÁGUA (IQA) MENSAL PARA CADA PONTO

Uma forma de verificar e monitorar os efeitos das atividades antrópicas sobre a qualidade hídrica de um ecossistema é o emprego de Índices de Qualidade da Água (IQA), que se baseiam principalmente em fatores limnológicos e físico-químcos [4]. Através dos resultados do IQA obtidos neste estudo, foi feita uma análise espacial por ponto amostrado, avaliando e caracterizando a qualidade da água de cada um.

Com relação ao parâmetro coliformes termotolerantes, onde os valores não foram determinados exatamente $(<3)$, foi utilizado o valor 3,0 para os cálculos do IQA. No mês de dezembro, o parâmetro nitrato não foi monitorado, e por isto, seu peso foi redistribuído para os outros parâmetros e o IQA foi calculado. Es- 
tes procedimentos também são adotados pelo IGAM no monitoramento das águas superficiais de Minas Gerais.

O IQA excelente não foi observado em nenhum ponto, assim como ocorre no estado de Minas Gerais. Esta condição vem sendo observada no desenvolvimento do projeto “Águas de Minas” desde 1997, na maioria dos corpos d'água monitorados pelo IGAM [28].

\section{Análise dos tributários}

Em uma análise mais ampla, o nível de qualidade da água dos afluentes variou de "ruim" a "bom".

Córrego da Grama (PT1):

Os valores de IQA variaram de 61,6 a 72,5. Este tributário apresentou predominância do nível de qualidade "médio" em 85,71 \% dos resultados. Levando-se em conta os pesos de cada parâmetro, a influência maior neste resultado deve-se aos altos valores de DBO e PT observados. O nível "bom" foi obtido em janeiro, correspondendo a 14,29\% dos resultados. Os parâmetros que influenciaram neste resultado foram os bons índices de OD e pH.

\section{Ribeirão dos Burros (PT2):}

Os valores de IQA variaram de 47,0 a 72,9. O principal afluente da represa apresentou $57,14 \%$ dos resultados com nível de qualidade classificado como "médio". A predominância de baixos valores de OD e pH, além de altos valores para a DBO contribuíram para este resultado. Em fevereiro e março, a qualidade foi "ruim", correspondendo a $28,58 \%$ do total analisado. Além dos parâmetros já citados, tiveram peso neste resultado, os altos valores para o PT. Em janeiro, a qualidade da água foi "boa", correspondendo a 14,28 \% dos resultados obtidos, sendo que s parâmetros de maior influência foram os baixos teores de nitrato e PT.

Análise do reservatório

De uma maneira geral, o nível de qualidade da água da represa variou de "médio" a "bom". A influência sazonal foi mais evidente no reservatório do que nos tributários.

\section{Ponto PR1:}

Os valores de IQA variaram de 63,6 a 72,2. Este ponto apresentou predominância do nível "médio" no período de cheia (dezembro de 2009 a abril de 2010), representando $71,43 \%$ do total de amostras analisadas. Valores que não atenderam à Resolução 357/05 do CONAMA [7], como aqueles referentes à DBO, $\mathrm{pH}$ e PT influenciaram nestes resultados. A água esteve com qualidade classificada como "boa" em $28,57 \%$ do total analisado, correspondendo aos meses de estiagem (maio e junho de 2010). Neste período, o pH foi próximo à neutralidade e a temperatura da água foi menor.

\section{Ponto PR2:}

Os valores de IQA variaram de 70,8 a 79,0. Nesta zona, o nível de qualidade no período estudado foi "bom", em 100,00 \% do total de amostras analisadas. Os parâmetros de maior peso que contribuíram positivamente para esses resultados foram: bons índices de OD (exceto em dezembro de 2009, janeiro e junho de 2010) e valores de $\mathrm{pH}$ próximos à neutralidade (exceto em janeiro de 2010), bem como menores valores de DBO (exceto em junho de 2010).

Este ponto da represa apresentou águas de melhor qualidade, se comparadas com PR1 e PR3. Acredita-se que as margens preservadas na direção e à montante do PR2 contribuíram para a manutenção da qualidade hídrica nesta zona. A margem direita, apesar das ocupações, possui mata densa e preservada. A margem esquerda não possui ocupações e não apresentou sinais de erosões. Apesar da ausência de mata ciliar, a cobertura do solo com gramíneas nesta margem ofereceu proteção, dificultando o carreamento de sedimentos para a água.

\section{Ponto PR3:}

Os valores de IQA variaram de 61,6 a 75,2 e o comportamento do PR3 foi semelhante ao PR1. Considerando o total analisado, o nível de qualidade foi "médio" em 71,43\% das amostras, no período de cheia (dezembro de 2009 a abril de 2010). Os parâmetros que tiveram maior peso nestes resultados foram altos valores de DBO e maiores temperaturas da água. O nível foi "bom" em 28,57\%, nos meses de estiagem (maio e junho de 2010). Contribuíram positivamente para esse resultado, os valores de $\mathrm{pH}$ mais próximos à neutralidade e menores valores de DBO e temperatura da água.

Esta deveria ser uma zona com águas de melhor qualidade, porém isso não foi observado. Acredita-se que esta região próxima à barragem sofre influência de processos que ocorrem à montante da represa, principalmente na margem direita entre o PR2 e o PR3, além de todas as interferências que ocorrem em toda a bacia.

ÍNDICE DE ESTADO TRÓFICO (IET) MENSAL PARA CADA PONTO

Carlson [29] afirma que o IET não equivale a um índice de qualidade de água. O termo qualidade está mais relacionado aos seus usos múltiplos e implica em um julgamento que deve ser separado do estado trófico. 
Em virtude da variabilidade sazonal dos processos ambientais que influenciam o grau de eutrofização dos corpos d'água, o IET pode apresentar variações no decorrer do ano. Sendo assim, na interpretação e análise das observações, é interessante considerar os resultados mensais para cada ponto amostral [30].

Os resultados de IET referentes aos tributários e à represa, bem como suas respectivas porcentagens, estão demonstrados na tabela 4.

Tabela 4 - Resultados de IET e porcentagens obtidas para cada estado trófico nos pontos amostrais dos tributários e da represa.

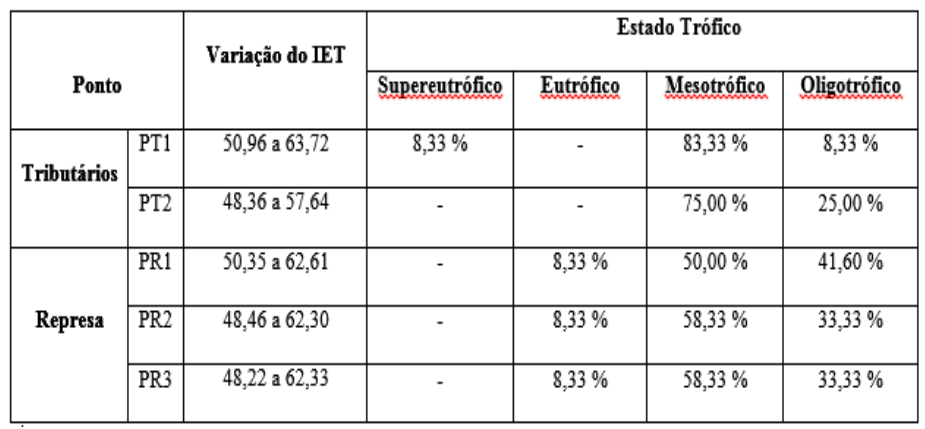

\section{Análise dos tributários}

\section{Córrego da Grama (PT1):}

Neste ponto, as águas do córrego e represa parecem se misturar. As características intermediárias entre os ambientes lótico e lêntico dificulta sua classificação em uma das categorias. No entanto, apesar do movimento lento de suas águas, as maiores médias de PT e menores médias de clorofila a (bases de cálculo do IET) levaram a classificar este ambiente em lótico, para fins de cálculo do IET (comparação feita com as médias do reservatório, sem considerar os desvios padrão).

O PT1 apresentou predominância do estado "mesotrófico" durante o período observado (Tabela 4). Em julho de 2009, a classificação foi "supereutrófico", justificado pelo pico observado para o PT em todos os pontos, além do valor de clorofila a acima da média para este ponto, na mesma amostra.

\section{Ribeirão dos Burros (PT2):}

O PT2 foi classificado como lótico para fins de cálculo do IET e apresentou estado "mesotrófico" predominante (Tabela 4). A infestação de macrófitas im- pede o curso normal do córrego, porém, o maior fluxo de água no ponto de coleta influenciou nos baixos índices de clorofila a obtidos. Consequentemente, houve menor tendência à eutrofização e os resultados do IET foram menores do que o PT1.

\section{Análise do reservatório}

Todos os pontos do reservatório foram classificados como lênticos para o cálculo do IET. Em uma primeira análise, o grau de trofia da represa variou de "oligotrófico" a "eutrófico". Porém, observou-se que a maior porcentagem dos resultados para cada ponto amostral demonstra o estado "mesotrófico" como característica predominante, indicando produtividade intermediária, com possíveis implicações sobre a qualidade e o uso da água.

Ao estudar os reservatórios de Billings, Barra Bonita, Itupararanga, Jaguari e Guarapiranga do estado de São Paulo, Lamparelli [14] observou que próximo à chegada dos rios formadores, os valores de IET foram superiores aos pontos próximos às barragens. No monitoramento da represa Dr. João Penido, houve somente três ocorrências deste tipo nos meses de novembro e dezembro de 2009 e junho de 2010, com valores decrescentes de IET do PR1 ao PR3, apesar da pouca diferença significativa entre os valores. Portanto, a tendência geral de apresentar características eutróficas na parte alta do reservatório e oligotróficas na zona próxima à barragem $[14,25,26]$ não foi observada.

As tendências de eutrofização puderam ser evidenciadas no mês de julho, representando 8,33\% das amostras analisadas em cada ponto, demonstrando alta produtividade do ecossistema em relação às suas condições naturais. Os picos de PT observados neste mês, aliados aos valores de clorofila a acima da média para todos os pontos do reservatório, justificaram a classificação "eutrófico" verificada.

Xavier, Dias e Brunkow [31] citam que o desenvolvimento da eutrofização em reservatórios, apesar de não impedir a utilização da água, encarece o tratamento e pode oferecer riscos à saúde humana, além das restrições aos seus usos múltiplos. Desta forma, considerando apenas a região próxima à ETA (PR3), a ocorrência do estado "eutrófico" em julho de 2009 indicou que o uso da água para abastecimento não foi aceitável. Considerando que os afluentes são fontes de abastecimento da represa, e que as comunidades podem utilizar essas águas para consumo, a abordagem feita pelos autores acima referidos [31] também foi utiliza- 
da como referência para verificar se os usos múltiplos foram comprometidos com relação aos estados tróficos. O grau "supereutrófico" observado em julho de 2009 para o ribeirão dos Burros (PT2) indicou uso tolerável da água apenas para a criação de espécies de peixes resistentes.

Na maior parte do período, o estado "mesotrófico" indicou que o uso para abastecimento de água potável foi tolerável para córregos e represa. $\mathrm{O}$ uso da água para processamento industrial, recreação de contato primário, criação de peixes sensíveis e paisagismo foi desejável, de acordo com a abordagem feita acima. Os períodos em que o estado "oligotrófico" foram observados indicaram que o uso da água para abastecimento foi desejável.

A análise ambiental de todos os resultados obtidos neste estudo ficou a cargo das observações e registros fotográficos feitos durante o monitoramento. Envolveu análises de natureza física, química e biológica, em relação às condições naturais e aos efeitos das ações antrópicas que puderam causar danos à saúde humana e aos ecossistemas estudados. As observações relacionadas neste estudo ficaram restritas às margens do manancial, porém, as alterações verificadas nas variáveis, podem não estar associadas a eventos de pequena magnitude e/ou esporádicos. Cabe evidenciar que tudo o que ocorre na bacia de drenagem reflete diretamente na qualidade dos corpos hídricos.

É pertinente ressaltar que a eficácia desta tentativa de se mensurar a qualidade da água, muitas vezes não corresponde à expectativa, pois a natureza apresenta a capacidade de resposta que nem sempre pode ser numericamente controlada pelo homem [22].

\section{CONCLUSÕES}

Diante de tudo o que foi exposto neste estudo, constatou-se que as formas de uso e ocupação do solo na área da bacia da represa Dr. João Penido, não têm sido adequadas para que o manancial seja utilizado para abastecimento de água de Juiz de Fora. Abaixo estão apresentadas diversas conclusões, de acordo com as abordagens na discussão dos resultados.

- A água demonstrou ser uma excelente indicadora da saúde sanitária e ambiental do ecossistema.

- Os resultados mostraram que o manancial vem sofrendo deterioração da qualidade das águas, provocada pelas ações antrópicas realizadas na região da bacia da represa, principalmente em suas margens. Os parâmetros que evidenciaram este fato foram: OD,
DBO, PT, pH e turbidez, que apresentaram desconformidades com a Resolução 357/05 do CONAMA [7] no período observado.

- Além da ocupação ilegal no entorno do manancial, as principais interferências antrópicas identificadas que possivelmente provocaram alterações na qualidade da água foram: movimentos de terra às margens da represa, remoção de macrófitas, lançamento inadequado de efluentes domésticos no tributário principal, retirada e queima de vegetação ciliar.

- Os resultados mostraram uma maior sensibilidade e vulnerabilidade dos afluentes em relação ao impacto das águas pluviais, se comparados ao reservatório.

- Os pontos próximos às zonas fluvial e lacustre são os mais impactados da represa, apresentando predominância do nível "médio" de qualidade da água. O ponto próximo à zona intermediária apresentou águas de melhor qualidade, com nível considerado "bom".

- A represa apresentou característica dominante de estado "mesotrófico" e seus usos múltiplos podem ter ficado comprometidos. Para abastecimento de água potável, foi considerado tolerável, na maior parte do período monitorado.

- É preciso adotar medidas mitigadoras visando a redução e controle do aporte de carga orgânica, nutrientes e sedimentos para a água, bem como a contenção do assoreamento e eutrofização dos corpos hídricos. Além de outras medidas, deve-se realizar o plantio de espécies adequadas, promovendo a recomposição da mata ciliar do manancial. Disciplinar e fiscalizar com mais rigor o uso e a ocupação do solo da bacia também é uma das importantes tarefas que devem ser promovidas para a sua preservação.

- É necessário dar prosseguimento aos estudos aqui apresentados para continuar avaliando os impactos provocados pelas interferências antrópicas. O monitoramento demonstrou ser ferramenta fundamental para a gestão integrada do manancial.

Espera-se que este trabalho de pesquisa seja útil para elaborar e executar planos de gestão ambiental integrada para a represa Dr. João Penido, conforme prevê a Política Nacional dos Recursos Hídricos [32]. Instituir programas de conservação é fundamental, porém, de nada adianta se as ações propostas não forem executadas realmente. Existem inúmeras leis que protegem os mananciais, mas aplicá-las efetivamente é muito mais importante. Constitui tarefa imprescindível das autoridades competentes e responsabilidade de todos nós, para que possamos garantir água de boa qualidade para os atuais e futuros usuários. 


\section{AGRADECIMENTOS}

Os autores agradecem ao $\mathrm{CNPq}$ pelo auxílio financeiro, e à Quarta Companhia de Polícia Militar Independente de Meio Ambiente e Trânsito ( $4^{\mathrm{a}}$ Cia PM Ind MAT) de Juiz de Fora, pelo auxílio na coleta das amostras.

\section{REFERÊNCIAS}

[1] Von Sperling, E., Morfologia de lagos e represas, Departamento de Engenharia Sanitária e Ambiental da Universidade Federal de Minas Gerais (DESA/UFMG), 1999.

[2] Carneiro, C., Pegorini, E. S., Andreoli, C. V., Em Gestão integrada de mananciais de abastecimento eutrofizados, Andreoli, C. V.; Carneiro, C., eds., Finep, Curitiba, 2005, cap. 1.

[3] do Carmo, M. S., Boaventura, G. R., Oliveira, E. C., Quím. Nova 28 (2005) 565.

[4] Carvalho, A. R., Schlittler, F. H. M., Tornisielo, V. L., Quím. Nova 23 (2000) 618.

[5] Dores, E. F. G. C., De-Lamonica-Freire, E. M., Quím. Nova 24 (2001) 27.

[6] Juiz De Fora. Prefeitura. Juiz de Fora Sempre. Plano Diretor de Desenvolvimento Urbano, FUNALFA Edições, Juiz de Fora, 2004.

[7] Conama; Resolução CONAMA no 357, de 17 de março de 2005.

[8] Leme Engenharia S.A. Plano Diretor de Abastecimento de Água da Área Urbana de Juiz de Fora. Recursos Hídricos. vol. IV/IX. Prefeitura de Juiz de Fora. Juiz de Fora, 1985 (acervo CESAMA).

[9] http:// www.cesama.com.br, acessada em fevereiro 2010.

[10] Juiz De Fora. Prefeitura. Ortofoto. Secretaria de Planejamento e Desenvolvimento Econômico (SPDE), Juiz de Fora, 2007.

[11] ABNT. NBR 9898. Preservação e técnicas de amostragem de efluentes líquidos e corpos receptores. Rio de Janeiro, 1987.

[12] APHA, AWWA, WPCF, Standard Methods for the Examination of Water and Wastewater, Clescerl, L. S., Greenberg, A. E., Eaton, A. D., eds.; 20th ed., Washington, American Public Health Association, 1998.

[13] Silva, N. da, Neto, R. C., Junqueira, V. C. A., Silveira, N. F. de A., Manual de métodos de análise microbiológica da água, Varela Editora e Livraria Ltda, São Paulo, 2005.

[14] Lamparelli, M. C.; Tese de Doutorado, Universidade de São Paulo, Brasil, 2004.

[15] Minas Gerais. Ministério Do Meio Ambiente (MMA). Secretaria de Estado do Meio Ambiente e
Desenvolvimento Sustentável de Minas Gerais (SEMAD). Sistema de cálculo da qualidade da água (SCQA): estabelecimento de equações do índice de qualidade das águas (IQA). Relatório 1, 2005. Belo Horizonte: MMA/SEMAD, 2005.

[16] Copam; Deliberação Normativa COPAM no 16 , de 24 de setembro de 1996.

[17] http://www.cetesb.sp.gov.br/Agua/rios/variaveis. asp\#cor, acessada em fevereiro 2010.

[18] Thornton, K. W. Em Reservoir limnology: ecological perspectives Reservoir limnology: ecological perspectives, Thorton, K.W, Kimmel, B. L., Payne, F. E., eds., John Wiley, New York, 1990, chap. 3.

[19] Fernandes, L. F., Lagos, P. D., Wosiack, A. C., Pacheco, C. V., Domingues, L., Zenhder-Alves, L., Coquemala, V., Em Gestão integrada de mananciais de abastecimento eutrofizados, Andreoli, C. V., Carneiro, C., eds., Finep, Curitiba, 2005, cap. 9.

[20] Esteves, F. de A, Fundamentos de Limnologia. 2. ed., editora Interciência, Rio de Janeiro, 1998.

[21] Ford, D. E. Em Reservoir limnology: ecological perspectives, Thorton, K.W, Kimmel, B. L., Payne, F.E., eds., John Wiley, New York, 1990, chap. 2.

[22] Silva, A. P. de S.; Dias, H.C.T.; Bastos, R.K.X.; Silva, E. Revista Árvore 33 (2009) 1063.

[23] Brasil; Lei no 9605, de 12 de fevereiro de 1998.

[24] Haddad, E. A.; Dissertação de Mestrado, Universidade Federal de Minas Gerais, Brasil, 2007.

[25] Kimmel, B. L., Lind, O.T., Paulson, L. J. Em Reservoir limnology: ecological perspectives, Thorton, K.W, Kimmel, B. L., Payne, F.E., eds.; John Wiley, New York, 1990, chap. 6.

[26] Pagioro, T. A., Roberto, M. do C., Thomaz, S. M., Pierini, S. A., Taka, M. Em Biocenose em reservatórios: padrões espaciais e temporais, Rodrigues, L., Thomaz, S. M., Agostinho, A. A., Gomes, L. C., org., RiMa, São Carlos, 2005, cap. 3.

[27] Conama, Resolução CONAMA no 274, de 29 de novembro de 2000.

[28] http://www.igam.mg.gov.br/images/stories/qualidade/relatorio-trimestra-1-trim-2010.pdf acessada em junho 2010.

[29] Carlson, R. E., Limnol. Oceanogr. 22 (1977) 361. [30] http://www.cetesb.sp.gov.br/Agua/rios/indice_iva iet.asp , acessada em julho 2009.

[31] Xavier, C. Da F., Dias, L. N., Brunkow, R. F., Em Gestão integrada de mananciais de abastecimento eutrofizados, Andreoli, C. V., Carneiro, C., eds., Finep, Curitiba, 2005, cap. 8.

[32] Brasil, Lei no 9433, de 08 de janeiro de 1997. 